\title{
A organização do espaço escolar na educação infantil
}

\begin{abstract}
Resumo: Este estudo teve a intenção de refletir sobre a importância do espaço escolar na Educação Infantil. A proposta do trabalho foi a de apresentar, por intermédio de pesquisa bibliográfica e da aplicação de um questionário junto aos educadores de uma escola municipal pública, do interior paulista, a percepção desses sujeitos sobre os espaços escolares e suas utilizações para o processo educativo de crianças menores. A análise dos dados coletados, quando cotejados com os referenciais que deram sustentação à pesquisa, mostra que não existe consenso entre os educadores sobre como deveriam ser organizados e disponibilizados os espaços escolares para as crianças na Educação Infantil. Os referenciais teóricos que utilizamos demonstram quão importante e fecundo podem ser esses espaços ocupados pelas crianças nas escolas de primeira infância, principalmente se forem adequados à exploração e às interações.
\end{abstract}

Palavras-chave: Educação; Política Educacional; Espaço Escolar; Educação Infantil.

\section{THE ORGANIZATION OF THE SCHOOL SPACE IN EARLY CHILDHOOD EDUCATION}

\begin{abstract}
This study was intended to reflect on the importance of school space in kindergarten. The purpose was to present, through bibliographic research and application of a questionnaire to teachers of a public municipal school, the perception of these subjects on the school spaces and their uses in the educational process of smaller children. The analysis of data collected, when collated with references that have supported research, shows that there is no consensus among educators about how they should be organized and available school spaces for children in kindergarten. The theoretical framework we use demonstrate how important and fruitful can be these occupied spaces by children in early childhood schools, especially if they are appropriate for exploration and interactions.
\end{abstract}

Keywords: Education; Educational politics; School space; Early Childhood education.

\footnotetext{
1 Livre docente vinculada ao Departamento de Educação e programa de Pós graduação em Educação da Universidade Estadual Paulista, campus de Presidente Prudente e coordenadora do Centro de Estudos em Leitura e Literatura Infantil e Juvenil (CELLIJ). Email: recellij@gmail.com

2 Doutora em Educação pelo Programa de Pós Graduação em Educação da Universidade Estadual Paulista Júlio de Mesquita FilhoMarília. Professora Assistente de Doutor da Universidade Estadual Paulista Júlio de Mesquita Filho - UNESP - Campus de Marília - RDIDPlotada no Departamento de Administração e Supervisão Escolar. E-mail: netezeu@gmail.com

3 Licencianda em Pedagogia pela Universidade Estadual Paulista Júlio de Mesquita Filho - UNESP - Campus de Marília. E-mail: belinha_roberto@hotmail.com
} 


\section{A importância da Educação Infantil como objeto de pesquisa}

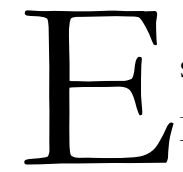

ste trabalho foi elaborado com foco na organização dos espaços escolares para atendimento da

Educação Infantil. O estudo do tema se justifica porque, desde a Constituição de 1988, a

Educação Infantil tem passado por uma série de revisões de suas concepções acerca da criança e educação em instituições públicas. Por outro lado, esse nível de ensino também passou por um processo de construção de novas práticas pedagógicas que contribuem para o desenvolvimento e as aprendizagens infantis. O nosso objetivo principal, ao realizar esta pesquisa, foi o de colaborar para ampliar a reflexão a respeito da organização dos espaços escolares e analisar quais as possíveis interferências que são advindas dessa organização sobre a aprendizagem da criança.

Este tema foi escolhido, com base nas observações feitas em uma escola de Educação Infantil pública desde 2014 até a presente data. Esta priorização também ocorreu em virtude de que as autoras, por estarem inseridas em práticas educacionais diárias, tanto como alunas quanto como professoras, puderam observar nos seus diferenciados percursos, que é no espaço físico escolar que a criança consegue estabelecer relações entre os conhecimentos adquiridos nos contextos sociais que vivenciam com o que está sendo trabalhado em sala de aula. É nesse local que a criança passa a compreender os significados de suas vivências escolares.

A Lei de Diretrizes e Bases da Educação Nacional - LDB no 9394/961, em seu artigo 29 estabelece que:

A Educação infantil, primeira etapa da educação básica, tem como finalidade o desenvolvimento integral da criança até seis anos de idade, em seus aspectos físico, psicológico, intelectual e social, complementando a ação da família e da comunidade (BRASIL, 1996)

Quando a legislação propõe como finalidade da Educação Infantil o desenvolvimento integral da criança, alguns questionamentos passam a fazer parte da preocupação dos estudiosos que pesquisam essa temática, como por exemplo: 1) A sala de aula é o único espaço de aprendizagem da criança? O pátio da escola, o parque e demais ambientes são destinados apenas à recreação? Qual a participação do 
movimento corporal na educação da criança na primeira infância? É possível compartimentalizar aspectos do desenvolvimento infantil (físico, intelectual, psicológico, social)? Quais as concepções dos profissionais da educação com relação à organização do espaço físico, materiais e seus efeitos sobre as práticas pedagógicas? Existe ainda o entendimento de que na sala de aula ocorre o desenvolvimento cognitivo e no pátio, o desenvolvimento físico e social? Como justificar a existência da intenção de controlar o corpo em atividades realizadas nas salas de aulas e concebidas na perspectiva do adulto, em que não há espaço para ações autônomas da criança?

Estas questões instigaram o trabalho investigativo que deu origem a este texto. No entanto, tínhamos clareza da impossibilidade de responder a todas nos limites da pesquisa que nos propusemos a realizar. Assim, procuramos realizar nossos estudos em uma escola de Educação Infantil, onde encontramos disponibilidade e aceitação dos profissionais educadores que ali exercem suas funções, buscando identificar nas suas respostas suas percepções sobre o espaço escolar e seus efeitos a respeito das aprendizagens das crianças.

Para darmos encaminhamento à pesquisa, optamos por priorizar a análise bibliográfica, realizando estudos sobre os referenciais teóricos que foram produzidos na área de conhecimento referente à "formação de educadores" e "organização dos espaços escolares". Nesta etapa pudemos identificar que, enquanto existe uma vasta produção teórica sobre a formação de educadores, não existe uma bibliografia igualmente robusta com relação à temática da organização de espaços escolares, e que, com relação a esse tema, a maioria das referências que encontramos são oficiais, disponibilizadas nos sites dos órgãos dos sistemas educacionais, em especial do MEC 4 . Também procuramos coletar dados por intermédio da aplicação de um questionário com sete questões abertas, que foi respondido por sete educadores que atuam em uma escola de Educação Infantil da rede municipal de uma cidade do interior paulista. Esses educadores atuam nas funções discriminadas no Gráfico 1:

\footnotetext{
${ }^{4}$ MEC - Ministério da Educação
} 


\section{Gráfico 1 - Função que ocupa na escola}

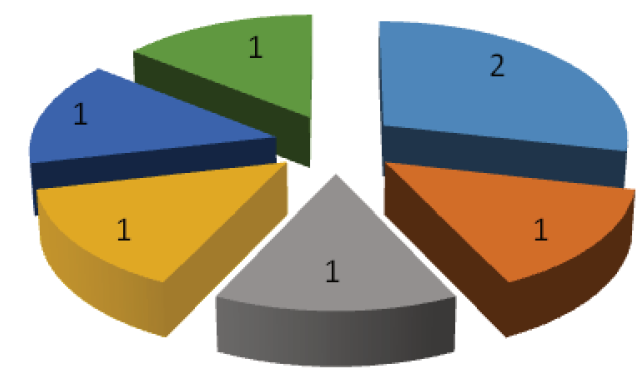

P1 - Professoras efetivas Maternal 1

P2 - Professora eventual Berçário 1

P3 - Professora efetiva, maternal 2

SE - Secretária de escola

DE - Diretora de escola substituta

- CP - Coordenadora

Pedagógica

Fonte: dados coletados pelas pesquisadoras

Os dados registrados no Gráfico 1, indicam que 3 dos sujeitos respondentes do questionário que aplicamos atuam na área da gestão escolar (SE; DE; CP), os demais são professores (P1A; P1B; P2; P3) que atuam nas salas de aula da Educação Infantil. A LDB, ao determinar a transferência das creches para o âmbito educacional, exige a formação em nível superior de todos os seus profissionais. Tais medidas criaram, em alguns momentos e locais, impasses entre as Secretarias Municipais de Assistência Social (cuidadores que não necessitam de formação específica) e as Secretarias Municipais de Educação (professores com formação em Pedagogia). Esses conflitos estavam relacionados às funções e equiparação de cargos dos profissionais que atuam na Educação Infantil. No entanto, ao realizarmos nossa coleta de dados, pudemos identificar que na escola objeto de nossa pesquisa, não ocorre esse conflito em razão da formação prevista na LDB para atuação nesse nível de ensino, está sendo garantida, conforme registra o Quadro 1:

\section{Quadro 1 - Formação dos profissionais que atuam na escola}

\begin{tabular}{|l|}
\hline QUESTÃO 2 - Qual a sua formação? \\
\hline P1A - Pedagogia e pós graduação em gestão escolar \\
\hline P1 B - Contabilidade e pedagogia \\
\hline P2 - Pedagogia e pós graduação em educação infantil; Bacharel em nutrição. \\
\hline P3 - Magistério e Pedagogia \\
\hline $\begin{array}{l}\text { SE - Letras, pós-graduação em Mídias na Educação e em Planejamento, Implementação e Gestão } \\
\text { da Educação a Distância. }\end{array}$ \\
\hline DE - Pedagogia \\
\hline
\end{tabular}


CP - Pedagogia; Pós graduação em Educação Inclusiva; Letras e cursando pós graduação em

Gestão Escolar.

Fonte: dados coletados pelas pesquisadoras

Nossa intenção ao questionar sobre a formação inicial desses profissionais era a de identificar se todos possuíam conhecimentos de natureza pedagógica para responder sobre o espaço em que atuam numa perspectiva fundamentada nos princípios educacionais. Assim, ao questionarmos esses sujeitos sobre a adequação ou não dos espaços escolares destinados à educação infantil, tínhamos a clareza de que eles teriam condições de fazer uma análise a partir da finalidade maior da escola que é a de garantir o desenvolvimento pessoal, a autonomia e a aptidão para o exercício pleno da cidadania.

É interessante observar que apenas a Diretora da Escola, que ocupa o cargo relativo à gestão escolar com maior responsabilização pelos sistemas educacionais, é a única profissional da escola que só possui o curso de Pedagogia. Os demais, ou possuem pós-graduação ou realizaram mais de um curso em sua formação inicial. Pensamos que esse é um dado a ser destacado, porque é importante o investimento nos sujeitos que atuam nessa etapa da escolaridade, uma vez que um dos grandes desafios da atualidade é ultrapassar a retórica da infância (FOCHI, 2015), para aprender a olhar a criança como ser pensante e darlhe espaço de expressão. A valorização da infância como categoria social, apesar de presente nos discursos acadêmicos e políticos, encontra pouco respaldo no cotidiano das instituições de Educação Infantil. Lembramos que o mundo contemporâneo, com suas demandas e as complexidades que lhe são inerentes, exige que os sujeitos se apropriem dos conhecimentos que são solicitados pela vida social que o compõe e torna isso cada vez mais necessário, uma vez que esse conhecimento é um dos fatores determinantes das desigualdades sociais existentes. O conhecimento produzido para além do senso comum, quando adquirido pelos sujeitos, desde o início da escolarização passa a ser um fator diferenciador entre pessoas e grupos sociais. Nesse aspecto, concordamos com Gatti (2014) sobre a forma de agir pedagogicamente, que traz para a discussão a questão da formação de professores. A formação docente, por ter natureza pedagógica, é ato político que implica em um "saber fazer" consciente, em que teoria e prática não se desassociam, é uma reflexão constante sobre as práticas e os espaços escolares em que elas ocorrem.

Se a Constituição de 1988 e a Lei de Diretrizes e Bases da Educação Nacional de 1996 são marcos históricos conceituais e simbólicos, por verem a criança de zero a seis anos como sujeito de direitos e proporem a igualdade de oportunidades para uma educação de qualidade, é preciso analisar como tais encaminhamentos são transformados em ações, tanto no que diz respeito à formação dos profissionais que se responsabilizam por essa educação, como também com relação aos espaços em que isso ocorre. Para superar posturas que não estão atentas a isso, é preciso valorizar os saberes profissionais (NÓVOA, 1995; KISHIMOTO, 1999) e caminhar em direção a uma melhoria dos espaços destinados à educação dessas crianças. 


\section{A Educação Infantil: contextos e textos}

Conforme a Lei de Diretrizes e Bases da Educação Nacional (BRASIL, 1996), a Educação Infantil é a primeira etapa da educação básica, tendo como finalidade o desenvolvimento integral da criança de até cinco anos, considerando-se suas particularidades física, psicológica, intelectual e social, integrando a ação da família e da comunidade. Nessa etapa de escolarização, as crianças com faixa etária até três anos são atendidas em creches, enquanto aquelas de quatro e cinco anos recebem atendimento nas chamadas préescolas. As Diretrizes Curriculares Nacionais para a Educação Infantil (BRASIL/DCNEI, 2010, p. 12), ao dispor sobre a oferta desse nível de escolarização determina que:

Primeira etapa da educação básica, oferecida em creches e pré-escolas, às quais se caracterizam como espaços institucionais não domésticos que constituem estabelecimentos educacionais públicos ou privados que educam e cuidam de crianças de 0 a 5 anos de idade no período diurno, em jornada integral ou parcial, regulados e supervisionados por órgão competente do sistema de ensino e submetidos a controle social. É dever do Estado garantir a oferta de Educação Infantil pública, gratuita e de qualidade, sem requisito de seleção.

Tanto no Referencial Curricular Nacional para a Educação Infantil (BRASIL/RCNEI, 1998) como nas Diretrizes Curriculares Nacionais para a Educação Infantil (BRASIL/DCNEI, 2009) a criança é compreendida como sujeito social, histórico e de direitos, integrante de uma família, estabelecida em uma sociedade com determinada cultura e em um tempo histórico específico. Essa criança sofre influências do contexto social em que vive, ao mesmo tempo em que o influencia, fazendo uso de diferentes linguagens e possibilidades em seu processo de construção de conhecimentos. Ela se beneficia das interações que estabelece nas práticas sociais cotidianas que lhe são oportunizadas. Nesses momentos, desenvolve sua identidade pessoal e coletiva. Nesses momentos, a criança "brinca, imagina, fantasia, deseja, aprende, observa, experimenta, narra, questiona e constrói sentidos sobre a natureza e a sociedade, produzindo cultura” (BRASIL/DCNEI, 2010, p. 12).

Na perspectiva histórica, a educação da criança brasileira esteve sob a responsabilidade exclusiva da família durante séculos. Era no convívio com os adultos e outras crianças do seu circulo familiar que ela participava das rotinas e tradições, aprendendo assim, as atitudes, normas e regras da sua cultura. Na sociedade contemporânea, por sua vez, a criança tem a oportunidade de frequentar um ambiente de socialização, convivendo e aprendendo sobre sua cultura mediante diferentes interações com seus pares. Como esclarecem Musatti e Mayer (2002, p. 198):

[...] nos primeiros anos de vida, as crianças estão profundamente engajadas em sua tentativa de organizar o mundo que as rodeia. Elas estão comprometidas em identificar e verificar as relações de similaridade e diferença entre objetos, as relações espaciais e os efeitos de uma ação realizada com um objeto sobre a localização e a identidade de outros objetos. 
Diante do que afirmam as citadas autoras, de que as crianças que estão na faixa etária relativa à Educação Infantil "estão comprometidas em identificar e verificar" inclusive as "relações espaciais", entendemos ser muito oportuno olhar com mais atenção à organização dos espaços escolares destinados à escolarização desse nível de ensino. Para isso, buscamos ouvir os protagonistas responsáveis por essa organização, ou seja, os gestores e professores de uma escola pública municipal de Educação Infantil.

\section{As perspectivas dos educadores sobre o trabalho na Educação Infantil}

Ao buscarmos o diálogo direto com os educadores que atuam em uma escola de educação infantil e que vivenciam cotidianamente a experiência do trabalho educativo nesse espaço, tínhamos como inspiração o pensamento de Contrerás e Lara (2010, p. 21), quando dizem:

É a experiência que nos imprime a necessidade de repensar, de voltar para as ideias que tínhamos sobre as coisas, porque justamente o que nos mostra a experiência é a insuficiência, ou a insatisfação, de nosso modo anterior de pensar. A necessidade da experiência e de parar-se nela, naquilo que nos provoca, se converte em uma origem e um caminho para a investigação, se é que consideramos a investigação parceira do pensamento, e não somente um procedimento, um esquema de atuação, que gera, por si mesmo seus próprios resultados.

Tendo como pressuposto que a "investigação" é "parceira do pensamento", questionamos os profissionais da escola objeto deste estudo, sobre os motivos que os levaram a optar por esse campo de atuação. Das respostas obtidas no questionário aplicado, elaboramos o Gráfico 2 para tornar visível aspectos quantitativos das respostas obtidas e o Quadro 2 para tornar mais evidente as opções assumidas por eles:

\section{Gráfico 2 - O que o (a) motiva na Educação Infantil?}

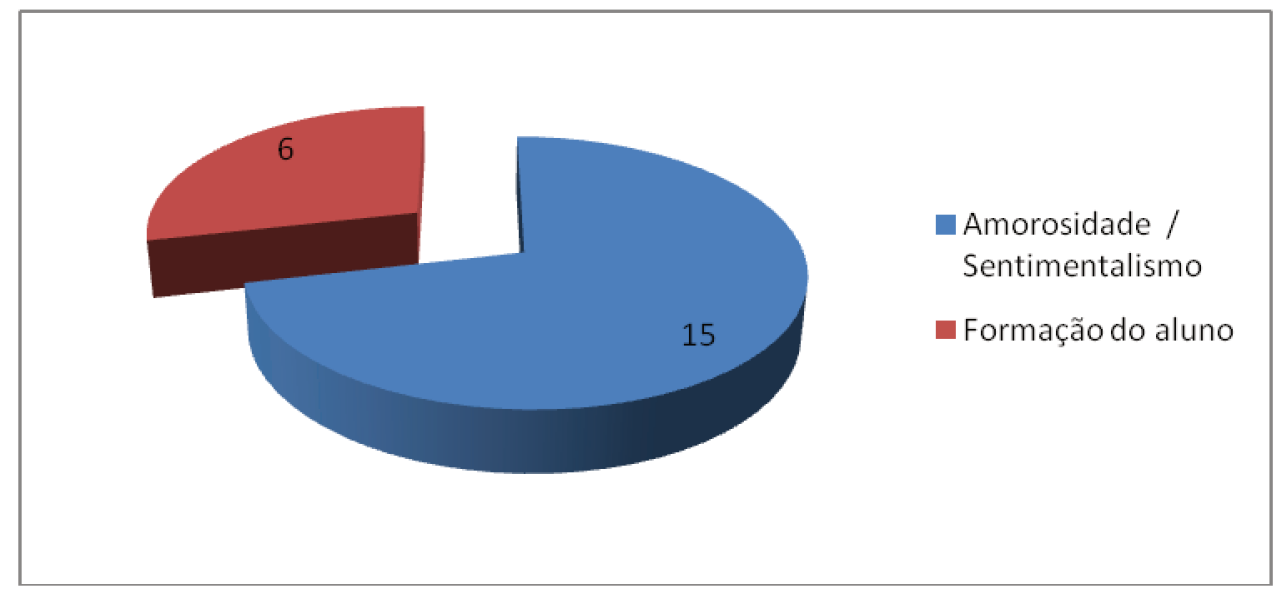

Fonte: dados coletados pelas pesquisadoras 


\section{Quadro 2 - Motivação para o trabalho}

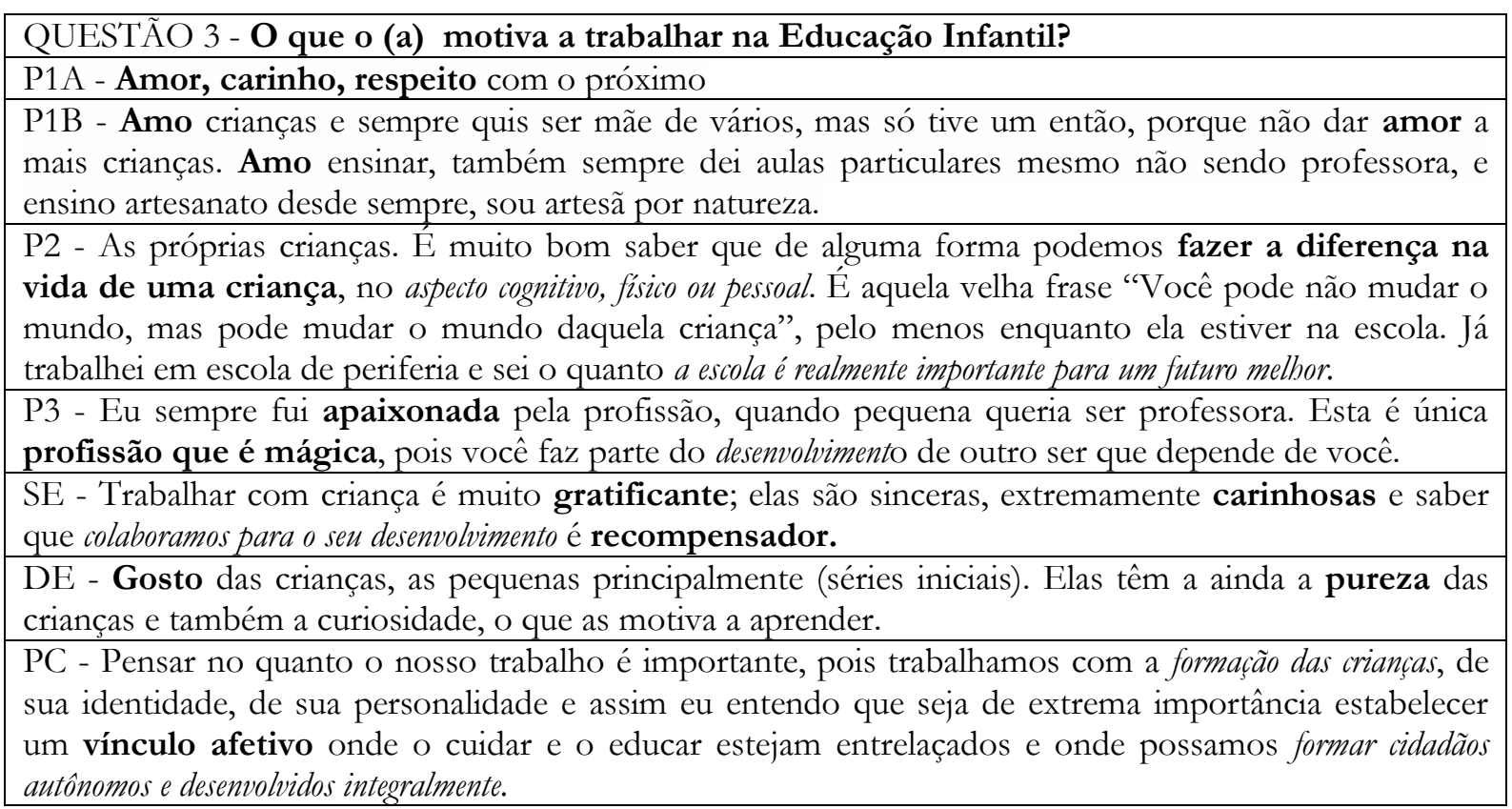

Fonte: dados coletados pelas pesquisadoras (grifo nosso)

Julgamos importante esclarecer que o uso do negrito e do itálico nos grifos acima tem a intenção de destacar alguns itens das respostas dadas pelos educadores, com a finalidade de diferenciar os aspectos que identificam as opções "sentimentais" (negrito) dos aspectos "formativos" (itálico). Fica evidente que a maioria absoluta dos respondentes opta por explicar sua preferência fundamentando seus argumentos na amorosidade e na afetividade. Expressões como "amor", "vínculo afetivo", "gratificante" e outras de mesma natureza, aparecem 15 vezes nas alegações dos professores sobre os motivos que os levaram a fazer a escolha por essa profissão. Com relação às motivações com caráter formativo identificamos, nas respostas obtidas, apenas 6 que teriam essa natureza. A ênfase nas questões sentimentais, na perspectiva assumida de que a Educação Infantil tem funções, não só sociais, mas também políticas e pedagógicas pode ser um fator complicador. $O$ trabalho na Educação Infantil deve contemplar o cuidado e o acolhimento, mas tem outras funções e perspectivas, como está descrito no Relatório de práticas cotidianas para a Educação Infantil, que estabelece para essa etapa da escolarização, o que segue:

Primeiramente uma função social que consiste em acolher, para educar e cuidar [...] em segundo lugar a função política de contribuir para que meninos e meninas usufruam de seus direitos sociais e políticos e exerçam seu direito de participação, tendo em vista a sua formação na cidadania. Por fim, a função pedagógica de ser um lugar privilegiado de convivência e ampliação de saberes e conhecimentos de diferentes naturezas entre crianças e adultos. A articulação entre essas três funções promove a garantia de bem-estar às crianças, aos profissionais e às famílias (BRASIL, 2009, p. 9 , grifo nosso). 
A necessidade de contemplar e articular essas três funções (social, política e pedagógica) solicita que os profissionais que organizam os espaços e tempos pedagógicos na Educação Infantil tenham uma visão plural e fundamentada sobre o seu papel e seus papéis nessa instituição. A partir do momento em que a formação das crianças pequenas deixou de ser uma responsabilidade familiar para se tornar uma responsabilidade social e coletiva, esse movimento deveria vir acompanhado da necessidade de se voltar para a experiência pedagógica e para a reflexão de como configurá-la. Apesar da produção acadêmica voltada para a Educação Infantil ter se ampliado de forma considerável nas últimas décadas (FOCHI, 2015), ainda há muito que realizar para constituir esse campo do saber para atender a complexa estrutura dessa etapa escolar. Concordamos com Bondioli (2004, p. 21) quando diz que é preciso “[...] refletir sobre o que se faz na escola com e para as crianças, sem abstrair essa ação do contexto no qual é concretamente realizada".

\section{Os discursos dos educadores sobre seus espaços de atuação}

É importante esclarecer no início desse tópico que o próprio conceito de espaço não é único e nem isento de interpretações a partir de diferentes referenciais teóricos. Para o filósofo francês René Descartes (1956 - 1650) o espaço é uma coisa que tem extensão, que ocupa um lugar, que tem tamanho. Como consequência desse modo de pensar, temos que o espaço pode ser medido. Já para um outro filósofo, o alemão Immanuel Kant (1724 - 1804), o espaço é uma intuição do ser humano, que existe como uma intuição elementar, que já nasce com as pessoas. Isso quer dizer que o espaço é uma ideia que cada um de nós já tem na cabeça a priori. É uma coisa que nasce com a gente e que serve para organizar todas as coisas materiais que existem. Piaget e Inhelder (1993) estabelecem uma relação intrínseca entre a noção de espaço e a de movimento, que chamam de ação.

Desde a gestação, quando na barriga da mãe a criança necessita de espaço para se desenvolver plenamente. Ao nascer, a criança também precisa de espaços que ofereçam liberdade de movimentos, segurança, construção de sua autonomia e interação com o mundo que a cerca. Segundo Piaget (apud KRAMER, 2000, p. 29), o "desenvolvimento resulta de combinações entre aquilo que o organismo traz e as circunstâncias oferecidas pelo meio [...]". Para Piaget, o espaço físico deve proporcionar desafios cognitivos; desafios estes que possam propiciar o desenvolvimento de novos esquemas, novas estruturas cognitivas e por fim, novos conhecimentos.

Se tomarmos como referência os estudos de Vygotsky (apud OLIVEIRA, 2008, p. 30) o espaço escolar surge como signo que interfere diretamente nas atividades psicológicas da criança. Para esse teórico os signos são marcas externas que auxiliam o homem em tarefas que exigem memória e atenção. “[...] A memória mediada por signos é, pois, mais poderosa que a memória não mediada". Dai a importância de um espaço que também sirva como instrumento mediador. Tudo o que compõe este espaço deve possibilitar o desenvolvimento cognitivo e sociocultural da criança. São as marcas externas do 
ambiente que possibilitarão o processo de internalização. Será a partir da internalização que o indivíduo passará a operar mentalmente.

Fica evidente assim, a importância dos espaços escolares destinados à formação da criança na Educação Infantil. Com essa perspectiva, fomos questionar aos gestores e professores da escola em questão, sobre a adequação (ou não) do espaço institucional que atuam para a garantia do desenvolvimento e das aprendizagens das crianças que ali são atendidas. Desses questionamentos colhemos os dados que estão registrados nos gráficos e quadros a seguir:

\section{Gráfico 3 - $O$ espaço físico dessa escola favorece a aprendizagem e desenvolvimento das crianças? Por quê?}

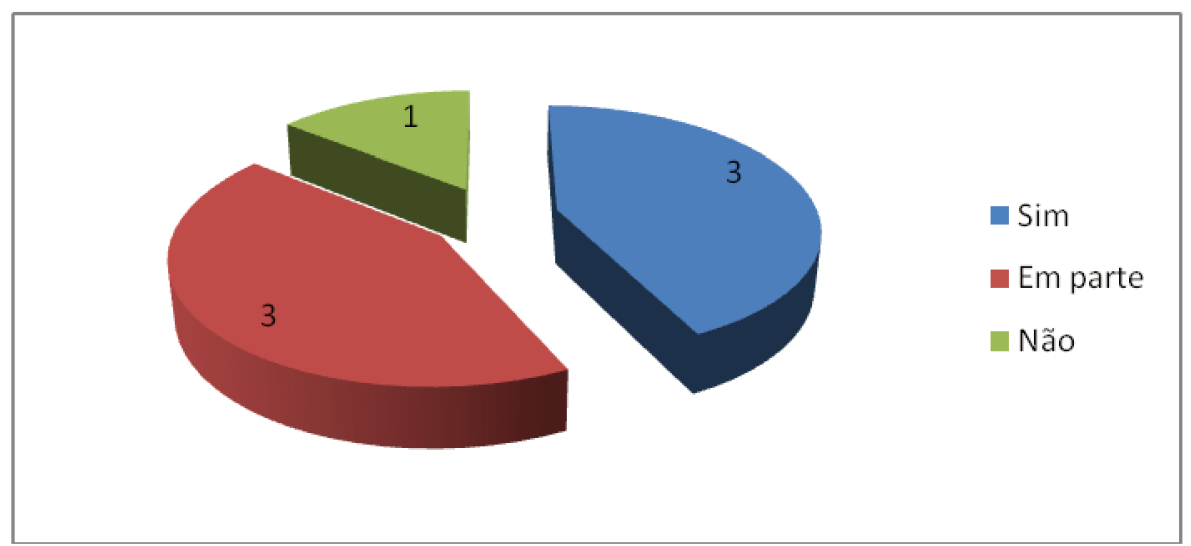

Fonte: dados coletados pelas pesquisadoras

\section{Quadro 3 - Adequação do espaço físico}

QUESTÃO 4 - $\mathrm{O}$ espaço físico dessa escola favorece a aprendizagem e desenvolvimento das crianças? Por quê?

P1A - Sim, o espaço favorece, porque é adequado.

P1B - Sim, porque o nível que estou a quantidade de alunos é suficiente.

P2 - Sim, porém claro que algumas alterações deveriam ser feitas em alguns espaços, principalmente no que se refere a tamanho para que pudéssemos usufruir de forma plena deles.

P3 - As salas de aulas são bem pequenas, mas sempre damos um jeito para proporcionar um ambiente acolhedor e propicio para a aprendizagem.

SE - Não. Porque, para a faixa etária atendida (de 0 a 4 anos), seria ideal conter, nessa escola, salas maiores, espaço externo coberto livre para realizar atividades diversificadas, uma quadra esportiva, o espaço ao ar livre existente necessita de árvores e plantas para as crianças terem contato com a natureza. DE - Escola com espaço físico muito amplo, o que possibilita o uso de diferentes estratégias de ensino. PC - Acredito que sim, embora ainda existam algumas falhas (como falta de sombra, por exemplo). Existe um bom espaço que pode ser explorado pelos professores e que muitas vezes não são aproveitados.

Fonte: dados coletados pelas pesquisadoras

Ao analisarmos as afirmações das respondentes pudemos identificar que apenas a Diretora da Escola entende que o espaço escolar destinado ao atendimento das crianças da Educação Infantil é "muito 
amplo" e "possibilita o uso de diferentes estratégias de ensino". Essa não é a opinião nem mesmo das demais gestoras. Todas as outras o veem como apenas "adequado" ou até mesmo como insuficiente. Isso causa preocupação, porque na escola, os gestores são corresponsáveis, junto com os demais educadores, pela organização e execução das atividades escolares das crianças. Eles planejam e organizam o currículo e determinam quais os espaços e os componentes físicos, como as edificações, os equipamentos e o mobiliário, que serão necessários à realização desse currículo. Assim, há vínculos diretos entre as ações dos gestores e das crianças e o espaço da escola.

Quando solicitamos que dessem sua impressão sobre a adequação dos espaços físicos, equipamentos e materiais, tendo como parâmetro os alunos a serem atendidos e a proposta pedagógica da escola, obtivemos as respostas que estão registradas nos Gráficos a seguir:

\section{Gráfico 4 - Os espaços físicos dessa escola são adequados e coerentes com base na quantidade de crianças e na faixa etária? Por quê?}

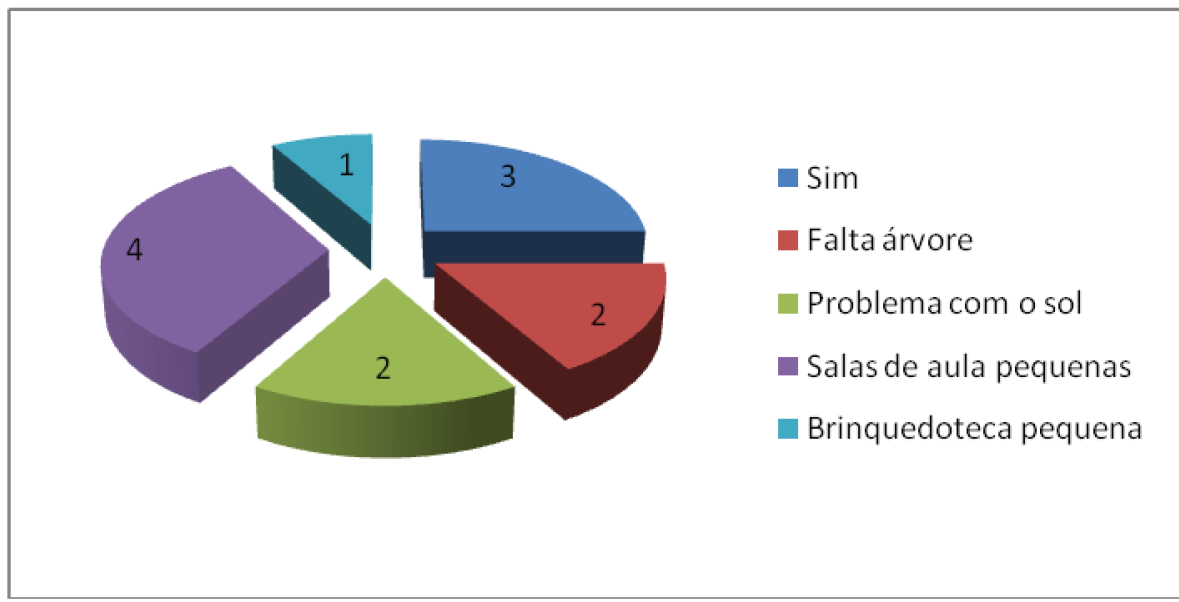

Fonte: dados coletados pelas pesquisadoras

Gráfico 5 - Os brinquedos são adequados para a idade das crianças que frequentam essa unidade escolar?

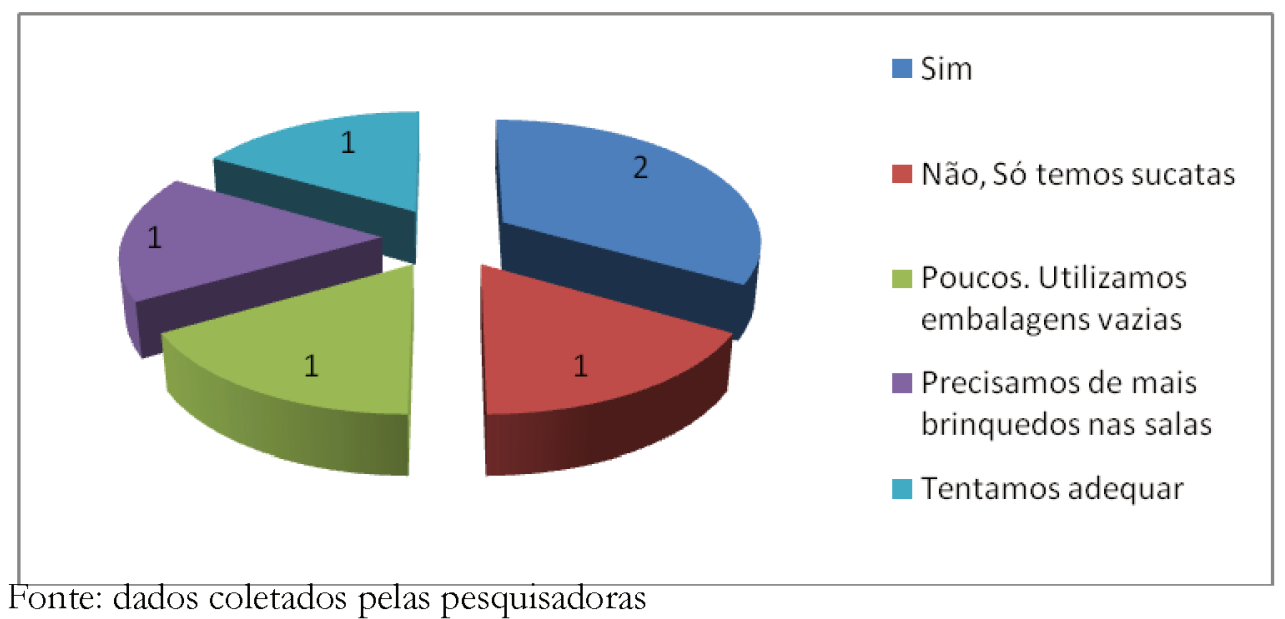




\section{Gráfico 6 - Há variedade de materiais, espaços e equipamentos para desenvolver diferentes atividades com as crianças?}

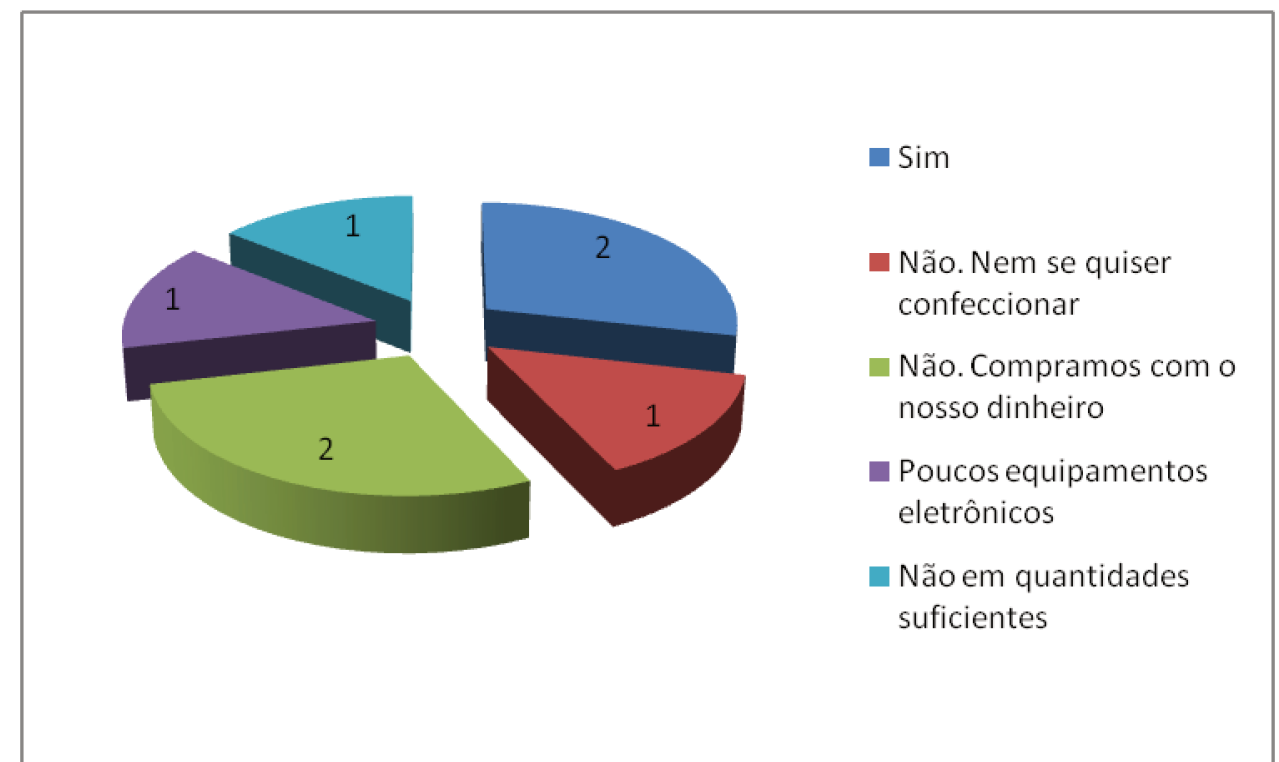

Fonte: dados coletados pelas pesquisadoras

Os dados coletados evidenciam que tanto os espaços fisicos, como os equipamentos e materiais utilizados nesses espaços não atendem às necessidades que são inerentes a um projeto pedagógico a ser desenvolvido em uma instituição dessa natureza e com a finalidade que lhe é precípua. Ao denunciarem essas dificuldades, os educadores demonstram a consciência de que um espaço escolar deve ter profissional qualificado e interessado em tentar mudar o que não está propício para o exercício de suas funções, buscando promover mudanças físicas, cronológicas, estruturais, lúdicas, etc. Para Redin (1998), isso só acontece com organização e intencionalidade. É preciso querer e estar disponível para que isso ocorra. É fundamental estar atento e entender como acontecem as aprendizagens nas crianças, suas descobertas, invenções, medos e encantamentos.

Todas as escolas que atendem às crianças na primeira infância deveriam ter uma boa infraestrutura, espaços bem organizados e próprios para receber os alunos dessa faixa etária, conforme orientam os Parâmetros Básicos de infraestrutura para instituições de Educação Infantil (BRASIL, 2006) quando anunciam que a edificação dessas instituições deve garantir:

A relação harmoniosa com o entorno, garantindo conforto ambiental aos seus usuários (conforto térmico, visual, acústico, olfativo/qualidade do ar) e qualidade sanitária dos ambientes;

A adequação dos ambientes internos e externos (arranjo espacial, volumetria, materiais, cores e texturas) com as práticas pedagógicas. 
Sabemos que organizar o espaço escolar não é tarefa fácil. Exige muito trabalho competente, técnico e compromisso político. Para que isso se concretize esse lugar deve privilegiar a formação integral das crianças, uma vez que:

O tempo e o espaço das relações da infância na família tem sua especificidade na fragilidade do ser infantil e na sua dependência, inicialmente total, depois vagarosamente relativizada nos aspectos físicos, intelectuais, emocionais e afetivos, de aprendizagens básicas para a sobrevivência e a convivência com outras pessoas e com o mundo (REDIN, 1998, p. 49)

Investigar o espaço escolar é fator importante para que seja possível compreender sua relação com o processo de aprendizagem. Sabemos que o lugar, por si só, não qualifica a educação, mas entendemos que é a partir dele que a criança amplia seu repertório cultural e garante seu desenvolvimento. Por isso, ele deve ser organizado de modo que atenda as necessidades sociais, cognitivas e emocionais dos alunos. Dessa forma, ao planejar as atividades e projetos a serem realizados na Educação Infantil devemos pensar nas maneiras de organizar os espaços de modo que se transformem em ambientes de aprendizagens, adequados e facilitadores daqueles saberes que pretendemos que as crianças adquiram, mantendo-se como uma estrutura de oportunidades e de ampliação das experiências significativas.

\section{Considerações finais}

A escrita deste texto ocorre a partir dos propósitos das pesquisadoras de começar um trabalho investigativo que no seu formato final pretende uma análise do papel do ensino da leitura na Educação Infantil. Iniciamos com esse estudo sobre o tema "A organização do espaço físico escolar a partir das expectativas dos sujeitos que atuam na Educação Infantil". Com este levantamento inicial tivemos o propósito de contribuir, ainda que de forma pontual e limitada, para os estudos da pedagogia da infância. Ao questionar os educadores sobre suas motivações para optar por trabalhar com crianças menores, pensamos em acolhê-los como companheiros dessa pesquisa, além de garantir que "suas vozes fossem ouvidas" pelos leitores deste texto. Isso porque acreditamos no que diz Freire (2011) que ter o que dizer não é privilégio de eleitos, mas direito de todos os homens. Esse exercício de escrita permitiu também interlocuções teóricas muito ricas.

A análise dos dados coletados mostra que não existe consenso entre os educadores sobre como deveriam ser organizados e disponibilizados os espaços escolares para as crianças na Educação Infantil. Alguns identificam os lugares como adequados, enquanto outros denunciam a inadequação dos mesmos. Pensamos que se houvesse sido oportunizada a eles uma reflexão anterior, com embasamento não só dos saberes da experiência, mas também com referenciais teóricos consistentes, cremos que, aí sim, seria mais fácil uma aproximação entre as expectativas que têm sobre os espaços educativos e o que conseguem enxergar nas suas práticas cotidianas. 
Concluímos declarando quão importante e fecundo podem ser os lugares ocupados pelas crianças. Principalmente se forem seguros e adequados à exploração e surgimento de relações com os outros, consigo mesmo e com o mundo que as cerca. Sendo assim, é importante que os espaços da Educação Infantil levem em consideração a atuação das crianças sobre eles, porque esse é o local onde submergem aprendizagens e descobertas. Quanto maior for a nossa consciência sobre isso, maior será a possibilidade de transformação desses espaços em verdadeiros territórios de aprendizagens. 


\section{Referências}

BONDIOLI, A. (Org.) O tempo no cotidiano infantil: perspectivas de pesquisa e estudo de casos. São Paulo: Cortez, 2004.

BRASIL, Lei de Diretrizes e Bases da Educação Nacional. Lei no 9.394/96, de 20 de dezembro de 1996.

BRASIL Ministério da Educação. Secretaria de Educação Fundamental. Referencial curricular nacional para a educação infantil / Ministério da Educação e do Desporto, Secretaria de Educação Fundamental. — Brasília: MEC/SEF, 1998.

BRASIL. Parâmetros básicos de infraestrutura para instituições de Educação Infantil. Brasilia: MEC, 2006. Disponível em http://portal.mec.gov.br. Acesso em 21/01/2016.

BRASIL Ministério da Educação. Práticas cotidianas na Educação Infantil: base para reflexão sobre as orientações curriculares. Brasilia: MEC, 2009. Disponível em http://portal.mec.gov.br/dmdocuments/relat seb_praticas cotidianas.pdf. Acesso em 21/01/2016.

BRASIL Ministério da Educação. Secretaria de Educação Básica. Diretrizes curriculares nacionais para a educação infantil / Secretaria de Educação Básica. - Brasília: MEC, SEB, 2010.

CONTRERÁS, J.; LARA, N. P. (Org.) Investigar La experiência educativa. Madri: Morata, 2010.

FREIRE, P. Pedagogia do Oprimido. 50ª ed. Rio de Janeiro: Paz e Terra, 2011.

FOCHI, P. Afinal, o que os bebês fazem no berçário? Comunicação, autonomia e saber-fazer de bebês em um contexto de vida coletiva. Porto Alegre: Penso, 2015.

GATTI, B. A. Formação inicial de professores para a educação básica: pesquisas e políticas educacionais. Revista Estudos em Avaliação Educacional. São Paulo, v. 25, n. 57, p. 24-54, jan./abr. 2014. Disponível em http://www.fcc.org.br/pesquisa/publicacoes/eae/arquivos/1899/1899.pdf. Acesso em 03/04/2016.

KISHIMOTO, T.M. Salas de aula de escolas infantis: domínio da fila, tempo de espera e falta de autonomia da criança. Nuances: Revista do Curso de Pedagogia, Presidente Prudente, v.5, n.4, p.1-7, 1999.

KRAMER, S. Com a pré-escola nas mãos. São Paulo: Ática, 2000.

MUSATTI, T.; MAYER S. Conhecendo e aprendendo em um contexto educacional: um estudo realizado nas creches de Pistóia. In: EDWARDS, C. GANDINI, I (org.), Bambini: a abordagem italiana à Educação Infantil. Porto Alegre: Artmed, 2002.

NÓVOA, A. (Coord.). Os professores e a sua formação. 2 ed. Lisboa: Dom Quixote, 1995.

OLIVEIRA, M. K. Vygotsky: Aprendizado e desenvolvimento. Um processo sócio-histórico. São Paulo: Ed. Scipione, 2008.

PIAGET, J.; INHELDER, B. A representação do espaço na criança. Porto Alegre: Artes Médicas, 1993.

REDIN, E. O espaço e o tempo da criança: se der tempo a gente brinca. Porto Alegre: Mediação, 1998. 
Recebido em: 03/08/2016 Aprovado em: 28/08/2016 